\title{
Efektivitas Penerapan Edukasi Sikap Kerja, Elektroterapi dan Terapi Latihan untuk Penderita Mechanical Neck Pain
}

\author{
Made Hendra Satria Nugraha ${ }^{1}$ Ni Komang Ayu Juni Antari ${ }^{2}$ Ni Luh Putu Gita Karunia \\ Saraswati $^{3}$ \\ ${ }^{1,2,3}$ Departemen Fisioterapi, Fakultas Kedokteran, Universitas Udayana \\ e-mail korespondensi: hendra_satria@unud.ac.id \\ doi:https://doi.org/10.24843/JEI.2019.v05.i02.p05 \\ Article Received: 02 September 2019; Accepted: 30 Desember 2019; Published: 31 Desember 2019
}

\begin{abstract}
Abstrak
Penyakit akibat kerja timbul akibat adanya ketidakseimbangan antara tugas dan kemampuan pekerja. Hal ini menimbulkan sikap kerja paksa seperti sikap kerja statis dan repetitif yang berlangsung terus-menerus. Hal ini dapat mengakibatkan terjadinya penyakit akibat kerja yang berdampak pada penurunan produktivitas kerja. Salah satu area yang mudah mengalami iritasi atau cedera adalah leher sebagai regio yang paling mobile sehingga perlu diberikan intervensi ergonomis. Adapun tujuan penelitian ini adalah untuk mengetahui efektivitas penerapan edukasi sikap kerja ergonomi, modalitas elektroterapi dan erapi latihan dalam menurunkan nyeri leher dan meningkatkan lingkup gerak sendi pada mechanical neck pain. Penelitian ini merupakan penelitian preeksperimental dengan one-group pre-test and post-test design. Hasil penelitian menunjukkan bahwa edukasi sikap kerja, penerapan elektroterapi dan terapi latihan dan dapat menurunkan nyeri leher $(\mathrm{p}<0,05)$ dan meningkatkan lingkup gerak sendi $(\mathrm{p}<0,05)$. Disimpulkan bahwa penerapan elektroterapi, terapi latihan, dan edukasi sikap kerja ergonomi dapat menurunkan nyeri leher dan meningkatkan lingkup gerak sendi pada mechanical neck pain.
\end{abstract}

Kata kunci: edukasi sikap kerja, elektroterapi, terapi latihan, mechanical neck pain

\section{The Effectiveness Of Work Posture Education, Electrotherapy Modality and Exercise Therapy In Individual With Mechanical Neck Pain}

\begin{abstract}
Occupational diseases arise due to inbalance between task and ability. This condition cause unsave work position such as static and repetitive positions continuously. It can result in occupational diseases and affect to decrease of work productivity. Among the body that is vulnerable to irritate or get injured is neck the most mobile region and need ergonomic intervention. The purpose of this study was to determine the effectiveness of work posture education, electrotherapy modality and exercise therapy in reducing neck pain and increasing the range of motion in mechanical neck pain. This study was a pre-experimental research using one-group pre-test and post-test design. The results showed that the application of work posture education, electrotherapy and exercise therapy can reduce neck pain $(p<0,05)$ and increase the range of motion $(p<0,05)$. It can be concluded that the application of work posture education, electrotherapy and exercise therapy can reduce neck pain and increase the range of motion in mechanical neck pain.
\end{abstract}

Keywords: work posture education, electrotherapy, exercise therapy, mechanical neck pain 


\section{PENDAHULUAN}

Penyakit akibat kerja timbul dikarenakan adanya ketidakseimbangan antara tugas, organisasi dan lingkungan terhadap kemampuan manusia yang melakukannya. Keadaan ini menimbulkan upaya adaptasi diantaranya dengan melakukan sikap kera paksa. Posisi statis dan repetitive yang berlangsung terus-menerus dapat mengakibatkan terjadinya penyakit akibat kerja yang berdampak pada penurunan produktivitas kerja (Natosba dan Jaji, 2016). Gangguan kesehatan akibat kerja yang sering ditemukan adalah yang berkaitan dengan musculoskeletal disorders. Menurut penelitian terdahulu, prevalensi orang yang menderita gangguan musculoskeletal di Inggris mencapai 572.000 pada tahun 2010 dan sekitar 230.000 orang menderita gangguan tubuh bagian atas serta leher (Putri, 2017).

Leher manusia adalah regio yang paling mobile dan rentan dengan iritasi atau cedera. Dua dari tiga orang umumnya mengalami nyeri leher selama hidupnya (Huldani, 2013). Prevalensi nyeri leher di masyarakat selama 1 tahun besarnya mencapai 40\%. Prevalensi ini lebih tinggi terjadi pada wanita. Pada pekerja prevalensi nyeri musculoskeletal di daerah leher berkisar antara 6-76\% selama 1 tahun. Kejadian ini terjadi lebih banyak pada wanita dibandingkan laki-laki (Samara, 2007). Beberapa faktor risiko yang berhubungan dengan timbulnya nyeri leher dan bahu pada pekerja kantor meliputi: jumlah jam kerja dengan komputer per hari, postur tubuh yang salah seperti posisi statis duduk lama pada satu posisi, bekerja dengan bahu terangkat, serta melakukan gerakan yang berulang-ulang. Hal ini didukung pula oleh penelitian Eltayeb S., et al., didapatkan empat prediktor utama keluhan leher dan bahu, seperti postur tubuh dan kepala yang ireguler, tuntutan pekerjaan, jumlah jam kerja per hari serta mempunyai riwayat keluhan sebelumnya (Silvia, dkk., 2007).

Salah satu keluhan muskuloskeletal yang dijumpai di daerah leher adalah mechanical neck pain. Apabila dikaji secara International Classification of Functioning, Disability, and Health (ICF) permasalahan mechanical neck pain meliputi nyeri, keterbatasan lingkup gerak sendi, serta disabilitas gerak pada sendi leher. Untuk mengatasi permasalahan tersebut, dibutuhkan intervensi ergonomis secara interdisiplin. Beberapa modal intervensi ergonomis yang dapat diterapkan diantaranya edukasi sikap kerja, elektroterapi dan terapi latihan. Beberapa penelitian terdahulu membuktikan bahwa pemberian ultrasound therapy, neck stabilization exercise, serta proprioceptive neuromuscular facilitation efektif dalam mengatasi mechanical neck pain (Dusunceli, dkk., 2009; Kumari, dkk., 2016; Soysal dan Aslan, 2013). Kombinasi berbagai modalitas diharapkan memberikan nilai lebih dalam menyelesaikan keluhan muskuloskeletal pada mechanical neck pain. Hal ini dapat diterapkan secara terintegrasi antara pengetahuan, sikap dan prilaku pekerja, sehingga hasil yang didapatkan lebih efektif dan efisien dengan berorientasi kepada pekera sebagai subjek yang harus dibuat menjadi sehat, aman, nyaman sehingga bisa bekerja secara produktif.

\section{METODE}

Penelitian ini merupakan penelitian pre-eksperimental dengan one-group pre-test and post-test design. Penelitian dilaksanakan di praktik mandiri fisioterapi di Kota Denpasar pada bulan Juli 2019. Mechanical neck pain termasuk ke dalam tipe nyeri non-radikular, sehingga apabila tes provokasi nyeri radicular negatif, maka nyeri tersebut dikarenakan adanya MNP.

Sampel yang berpartisipasi adalah 12 orang sesuai kebutuhan sampel minimal (Poccock, 2008). Sebelum intervensi, sampel dilakukan pengukuran awal. Pengukuran awal meliputi: tingkat nyeri gerak ketika melakukan gerakan lateral fleksi leher dengan visual analogue scale serta keterbatasan lingkup gerak sendi ketika gerakan lateral fleksi leher dengan menggunakan goniometer. Intervensi diberikan sebanyak tiga kali dan diakhir sesi dilakukan kembali pengukuran post-test. 
Intervensi yang berikan meliputi: edukasi postur kerja ergonomis, ultrasound therapy, neck stabilization exercise, proprioceptive neuromuscular stabilization. Edukasi postur kerja diaplikasikan melalui posisi duduk yang ergonomis yaitu suatu keadaan mempertahankan postur badan yang stabil dengan memenuhi kaidah: sesuai dengan kondisi fisiologi, menyenangkan dalam jangka waktu tertentu, sesuai dengan pekerjaan yang dilakukan. Selain itu, prinsip duduk yang normal meliputi: lutut fleksi 90 derajat, tubuh fleksi di atas 90 derajat, pelvis rotasi ke belakang 30 derajat atau lebih, berat badan bertumpu pada ischial tuberositas, serta bagian atas tulang sacrum lebih horizontal (Nilamsari dkk., 2015). Posisi yang dihindari untuk mengurangi keluhan nyeri leher, meliputi: gerakan bahu lebih dari 15 kali per menit, duduk saat bekerja dengan durasi $>95 \%$ lama kerja, fleksi leher lebih dari 20 derajat dengan total durasi 66-70\% lama kerja, fleksi leher lebih dari 45 derajat dengan total durasi 10\% lama kerja, serta kontraksi, beban, dan posisi statik (Samara, 2007).

Ultrasound therapy diaplikasikan pada area yang akan diterapi dengan frekuensi 1 $\mathrm{MHz}$, intensitas 2,0W/cm², serta durasi selama 10 menit (Michlovitz, dkk., 2012). Neck stabilization exercise (NSE) adalah pelatihan yang didesain untuk mengembalikan daya tahan serta koordinasi otot-otot pada sendi leher. NSE dilakukan melalui gerakan cervical extension, chin tuck, shoulder rolls, shoulder shrugs, dan scapular retraction. Keseluruhan gerakan dilakukan sebanyak 15 kali (Kaka, dkk., 2015). Aplikasi penerapan proprioceptive neuromuscular stabilization (PNF) dilakukan melalui gerakan: (1) Fleksi kepala dan leher dengan rotasi ke kanan, (2) Fleksi kepala dan leher dengan rotasi ke kiri, (3) ekstremitas atas dengan dua pola. Setiap gerakan dilakukan 8 - 12 kali repetisi (Kumari, dkk., 2016).

\section{HASIL DAN PEMBAHASAN}

Hasil penelitian pada 12 sampel didistribusikan berdasarkan jenis kelamin dan usia dipaparkan pada Tabel 1.

Tabel 1

Distribusi Data Sampel Berdasarkan Jenis Kelamin dan Usia $(\mathrm{n}=12)$

\begin{tabular}{cc}
\hline Karakteristik & Frekuensi $(\%)$ \\
\hline Jenis Kelamin $(\%)$ & \\
Laki-laki & $3(25,00)$ \\
Perempuan & $9(75,00)$ \\
Usia (tahun) & \\
Rerata \pm SB & $34,67 \pm 4,03$ \\
\hline
\end{tabular}

Berdasarkan Tabel 1 terlihat bahwa, sampel berjenis kelamin laki-laki sebanyak 3 orang $(25 \%)$ dan perempuan sebanyak 9 orang $(75 \%)$.

Sebagai prasyarat uji statistik dalam penelitian, maka digunakan uji normalitas dan homogenitas sebelum dan setelah intervensi. Shapiro wilk test digunakan untuk uji normalitas, sedangkan Levene's test digunakan untuk uji homogenitas. Hasil uji diperlihatkan pada Tabel 2.

Tabel 2

Hasil Uji Normalitas dan Homogenitas Sebelum dan Sesudah Intervensi

\begin{tabular}{ccc}
\hline \multirow{2}{*}{ Kelompok Data } & Uji Normalitas $^{\mathrm{a}}$ & Uji Homogenitas $^{\mathrm{b}}$ \\
\cline { 2 - 3 } & $\begin{array}{c}\text { Kelompok perlakuan } \\
\text { (nilai p) }\end{array}$ & $\begin{array}{c}\text { Kelompok } \\
\text { perlakuan (nilai p) }\end{array}$ \\
\hline
\end{tabular}




\begin{tabular}{llc}
\hline Skor Nyeri Sebelum Intervensi & 0,773 & 0,778 \\
Skor Nyeri Setelah Intervensi Skor & 0,450 & \\
ROM Sebelum Intervensi Skor & 0,767 & 0,937 \\
ROM Setelah Intervensi & 0,971 & \\
\hline a: Shapiro Wilk test & & \\
b: Levene's test & &
\end{tabular}

Berdasarkan Tabel 2 terlihat bahwa data berdistribusi normal $(\mathrm{p}>0,05)$ dan homogen. $(\mathrm{p}>0,05)$. Berdasarkan hasil uji normalitas, maka uji yang digunakan untuk pengujian hipotesis adalah uji statistik parametrik.

Paired sample t-test digunakan untuk menguji rerata penurunan nilai nyeri dan peningkatan lingkup gerak sendi sebelum dan setelah intervensi. Hasil uji tertera pada Tabel 3.

Tabel 3

Hasil Analisis Skor Nyeri dan Lingkup Gerak Sendi

\begin{tabular}{lccc}
\hline \multirow{2}{*}{ Kelompok Data } & $\begin{array}{c}\text { Sebelum } \\
\text { Intervensi }\end{array}$ & $\begin{array}{c}\text { Setelah } \\
\text { Intervensi }\end{array}$ & \multirow{2}{*}{ Nilai p } \\
\cline { 2 - 4 } & Rerata \pm SB & Rerata \pm SB & \\
\hline Nyeri & $5,85 \pm 1,08$ & $4,30 \pm 1,11$ & 0,000 \\
Gerak Sendi & $32,89 \pm 0,88$ & $34,71 \pm 0,91$ & 0,000 \\
\hline
\end{tabular}

Berdasarkan Tabel 3 didapatkan hasil penurunan nilai nyeri dan peningkatan lingkup gerak sendi pada kelompok perlakuan berbeda bermakna $(\mathrm{p}<0,05)$ yang berarti bahwa terdapat penurunan nyeri dan peningkatan lingkup gerak sendi sebelum dan setelah intervensi.

Hasil penelitian menunjukkan bahwa terdapat penurunan nyeri dan peningkatan lingkup gerak sendi pada mechanical neck pain. Hal ini sesuai dengan penelitian Soysal dan Aslan (2013) yang mengaplikasikan ultrasound therapy sebanyak 14 sesi selama 3 minggu dan didapatkan hasil penurunan nyeri, disabilitas, dan peningkatan kualitas hidup yang signifikan pada penderita non-spesific neck pain. Selain itu, penelitian Celik, dkk. (2013) membandingkan penggunaan ultrasound therapy metode continues dengan intermittent. Hasil penelitian menunjukkan terjadi peningkatan ambang rangsang nyeri pada kelompok ultrasound therapy baik yang diaplikasikan metode continues atau intermittent. Sementara itu aplikasi ultrasound therapy dengan metode continues dapat meningkatkan cervical ROM pada tiga bidang, sehingga pengaplikasian ultrasound therapy dengan metode continues lebih efektif dalam meningkatkan ambang rangsang nyeri dan ROM pada mechanical neck pain.

Draper menjelaskan efek therapeutic ultrasound pada berbagai intensitas pada otot triceps surae yang tidak mengalami cidera pada mahasiswa (Michlovitz, dkk., 2012). Suhu permukaan otot meningkat menjadi $4^{\circ} \mathrm{C}$ dengan durasi 2,5 menit dengan intensitas $2,0 \mathrm{~W} / \mathrm{cm}^{2}$ menggunakan frekuensi $3 \mathrm{MHz}$. Tetapi untuk dapat meningkatkan suhu jaringan otot yang lebih dalam, dibutuhkan waktu selama 10 menit dengan intensitas $2,0 \mathrm{~W} / \mathrm{cm}^{2}$ pada frekuensi 1 MHz. Implikasinya adalah ketika pengaplikasian dengan waktu yang lebih lama dan intensitas yang lebih besar maka dapat efek panas yang lebih besar pada jaringan otot yang lebih dalam ketika aplikasi menggunakan $1 \mathrm{MHz}$ dan jaringan otot yang superficial dengan menggunakan $3 \mathrm{MHz}$.

Penelitian Dusunceli, dkk. (2009) meneliti pemberian physical therapy agents (PTA) dan neck stabilization exercise dengan membandingkan pemberian PTA dengan isometric dan stretching exercise, serta kelompok dengan pemberian PTA saja selama 3 minggu. Hasil 
penelitian menunjukkan bahwa kombinasi PTA dan NSE lebih efektif dalam menurunkan nyeri dan disabilitas pada mechanical neck pain. Penelitian lainnya dari Akodu, dkk. (2018) menyimpulkan bahwa pemberian NSE 2 kali seminggu selama 8 minggu dapat menurunkan nyeri dan disabilitas serta perbaikan terhadap tingkat kecemasan dan depresi dan meningkatkan sudut craniovertebra. Selain itu, penelitian Kaka, dkk. (2015) menunjukkan bahwa pemberian NSE 3 kali seminggu selama 8 minggu mampu menurunkan nyeri dan disabilitas fungsional pada penderita non-specific neck pain. Penelitian Parisa, dkk. (2016) membandingkan antara pemberian intervensi NSE dan proprioceptive neuromuscular facilitation (PNF) selama 8 minggu (6 sesi per minggu dan 2 sesi per hari). Studi ini membuktikan bahwa NSE lebih efektif daripada PNF dalam mengurangi nyeri dan disabilitas serta meningkatkan cross-sectional area dari otot deep flexor.

Penelitian Kumari, dkk. (2016) menjelaskan bahwa aplikasi PNF selama 12 sesi (3 kali seminggu selama 4 minggu) mampu menurunkan nyeri, meningkatkan ROM, dan memperbaiki disabilitas leher pada penderita mechanical neck pain. Penelitian Roodt (2009) membuktikan bahwa penerapan PNF selama 6 sesi dalam 3 minggu mampu meningkatkan ROM, ambang rangsang nyeri yang dievaluasi dengan algometer, serta memperbaiki disabilitas leher pada penderita chronic mechanical neck pain. Penelitian ini membandingkan dua metode terapi lainnya, yaitu muscle energy technique dan spinal manipulative therapy. Hasil penelitian menunjukkan bahwa pengaplikasian PNF lebih efektif dalam meningkatkan ROM ekstensi leher dibandingkan dengan penerapan kedua metode terapi lainnya.

Narrative review Sharman, dkk. (2006) merekomendasikan bahwa teknik PNF yang mengkombinasikan kontraksi konsentrik pada opposite muscle dan kontraksi statis pada target muscle lebih efektif. Aplikasi PNF selama dua kali seminggu dalam satu kali repetisi efektif dalam meningkatkan ROM. Dalam penelitian Etnyre dan Lee (1988) terdapat peningkatan $21^{\circ}$ setelah diaplikasikan PNF 2 kali seminggu selama 12 minggu. Kontraksi statis diberikan sebesar $20 \%$ dari target muscle untuk meningkatkan ROM dan ditahan selama 3 detik. Ketika menggerakkan target muscle ke posisi teregang, teknik ini harus dilakukan dengan kecepatan yang rendah untuk mencegah peningkatan kekakuan dari target muscle atau stretch reflex dan mencegah peningkatan tahanan viscous.

Mekanisme kerja dari PNF berkaitan dengan efek autogenic inhibition dan reciprocal inhibition. Autogenic inhibition diaplikasikan melalui pemberian tahanan secara isometrik pada target muscle. Hal ini menyebabkan peningkatan inhibisi dari Ib-inhibitory interneurons yang mengakibatkan pengurangan tingkat eksibilitas dari target muscle yang pada akhirnya akan menfasilitasi terjadinya peregangan. Sedangkan reciprocal inhibition diaplikasikan melalui kontraksi secara konsentrik pada opposing muscle akan mengakibatkan penurunan aktivitas pada target muscle. Hal ini berkaitan dengan input dari Ia-afferent opposing muscle terhadap eksitasi dari Ia inhibitory motorneurone yang menyebabkan inhibisi atau penurunan tingkat aktivitas pada target muscle alpha-motorneurone yang pada akhirnya memfasilitasi terjadinya peregangan (Sharman, dkk., 2006).

Edukasi terkait sikap kerja ergonomi dapat memberikan kemudahan bagi para pekerja. Dengan edukasi ergonomi, kendala keterbatasan yang dimiliki dapat diatasi. Penerapan edukasi ergonomi dilakukan melalui sikap kerja yang terdiri atas: sikap duduk dan berdiri. Sikap yang disarankan meliputi: posisi kaki yang tidak terbebani oleh berat tubuh dan stabil saat bekerja, sedangkan untuk sikap berdiri yaitu posisi vertebra dan berat badan bertumpu secara seimbang pada kedua kaki. Selain itu, tata letak tempat kerja yang berhubungan saat melakukan aktivitas kerja serta jarak jangkauan dan kegiatan mengangkat beban dapat disesuaikan. Duduk merupakan sikap yang memiliki banyak keuntungan, diantaranya: penurunan pembebanan kaki serta pemakaian energi untuk sirkulasi bisa dikurangi. Namun, sikap duduk dalam jangka waktu yang lama dapat menyebabkan kejadian nyeri punggung bawah dimana otot punggung menjadi kaku dan otot core yang menstabilisasi tulang 
belakang mengalami kelemahan. Desain stasiun kerja disertai sikap ergonomi dapat mengurangi kelelahan dan keluhan subjektif bila berkerja lebih dari 2 jam (Novianti dan Tanjung, 2016). Sikap duduk yang ergonomis yaitu suatu keadaan mempertahankan postur badan yang stabil dengan memenuhi kaidah: sesuai dengan kondisi fisiologi, menyenangkan dalam jangka waktu tertentu, sesuai dengan pekerjaan yang dilakukan. Selain itu, prinsip duduk yang normal meliputi: lutut fleksi 90 derajat, tubuh fleksi di atas 90 derajat, pelvis rotasi ke belakang 30 derajat atau lebih, berat badan bertumpu pada ischial tuberositas, serta bagian atas tulang sacrum lebih horizontal (Nilamsari dkk., 2015). Sikap yang dihindari untuk mengurangi keluhan nyeri leher, meliputi: gerakan bahu lebih dari 15 kali per menit, duduk saat bekerja dengan durasi $>95 \%$ lama kerja, fleksi leher lebih dari 20 derajat dengan total durasi 66-70\% lama kerja, fleksi leher lebih dari 45 derajat dengan total durasi 10\% lama kerja, serta kontraksi, beban, dan posisi statik (Samara, 2007).

\section{SIMPULAN}

Berdasarkan hasil penelitian dan pembahasan, maka dapat disimpulkan bahwa edukasi sikap kerja penerapan elektroterapi, terapi latihan, dan dapat menurunkan nyeri dan meningkatkan lingkup gerak sendi pada penderita mechanical neck pain.

\section{DAFTAR PUSTAKA}

Akodu, A. K., Odunsi, F. A., dan Giwa, S. O. 2018. Effects of Neck Stabilization Exercise on Pain, Disability, Craniovertebral Angle and Psychological Status in Patient with Non-Specific Chronic Neck Pain. JRCRS,10-15

Celik, O., Ketencil, A., Esmaeilzadeh, S., dan Sindel, D. 2013. The Effectiveness of Therapeutic Ultrasound in Non-Specific Mechanical Cervical Pain and Comparison of Different Application Methods for Clinical Practice. URL: https://ard.bmj.com/content/72/Suppl 3/A992.3

Dusunceli, Y., Ozturk, C., Atamaz, F., Hepguler, S., dan Durmaz, B. 2009. Efficacy of Neck Stabilization Exercises for Neck Pain: A Randomized Controlled Study. J.Rehabil Med, Vol. 41:626-631.

Etnyre, B. R dan Lee, E. J. 1988. Chronic and acute flexibility of men and women using three different stretching techniques. Res Q, Vol. 59(3):222-228

Huldani. 2013. Neck Pain (Nyeri Leher). Banjarmasin: Universitas Lambung Mangkurat.

Kaka, B., Ogwumike, O. O., Ogunlade, S. O., Adeniyi, A. F. 2015. Effects of neck stabilization and dynamic exercises on pain, disability and fear avoidance beliefs in patients with non-specific neck pain; a randomized clinical trial. Arch Physiother Glob Res, Vol. 19(3):17-29.

Kumari, C., Sarkar, B., Banerjee, D., Alam, S., Sharma, R., Biswas, A. 2016. Efficacy of Muscle EnergyTechnique as Compared to Proprioceptive Neuromuscular Facilitation Technique in Chronic Mechanical Neck Pain: A Randomized Controlled Trial. International Journal of Health Sciences \& Research, Vol. 6(11): 152 - 161.

Michlovitz, S. L., Bellew, JW., Nolan-Jr, T. P. 2012. Modalities for Therapeutic Intervention. Fifth Edition. Philadelphia: Davis Company.

Natosba, J dan Jaji. 2016. Pengaruh Posisi Ergonomis terhadap Kejadian Low Back Pain pada Penenun Songket di Kampung BNI 46. Jurnal Keperawatan Sriwijaya, Vol. 3(2).

Novianti, M. D. dan Tanjung, S. 2016. Analisis Perbaikan Postur Kerja Operator pada Proses Pembuatan Pipa untuk Mengurangi Musculoskeletal Disorders dengan Menggunakan Metode RULA. Jakarta: Seminar Nasional Sains dan Teknologi 
Parisa, G. H., Ahmadreza, A. A., Mohammad, H., Asghar, A., Leila, R., Fateme, G. 2016. Investigating the effect of stabilization exercise and proprioceptive neuromuscular facilitation exercises on cross-sectional area of deep cervical flexor muscles in patients with chronic non-specific neck pain. International Journal of Medical Research \& Health Sciences, Vol. 5(11):502-508.

Poccok, S. 2008. Clinical trials. England: John Wiley\&Sons Ltd.

Putri, V. R. A. 2017. Hubungan Postur Kerja Tidak Ergonomis dan Karakteristik Responden dengan Musculoskeletal Disorders (MSDs) pada Pekerja Furniture di CV Nova Furniture Boyolali (Skripsi). Surakarta: UMS

Roodt, M. L. E. 2009. "A Comparative Study of Three Different Types of Manual Therapy Techniques in the Management of Chronic Mechanical Neck Pain" (dissertation). Durban: Faculty of Health at the Durban University of Technology.

Samara, D. 2007. Neck musculoskeletal among workers with static position. Universa Medicina, Vol. 26(3): 137-142.

Sharman, M. J., Cresswell, A. G., dan Riek, S. 2006. Proprioceptive Neuromuscular Facilitation Stretching Mechanisms and Clinical Implications. Sports Med, Vol. 36 (11):929-939.

Silvia, N., Widyahening, I. S., dan Soemarko, D. S. 2007. Efektivitas Latihan Leher dan Bahu dalam Mengurangi Nyeri Leher dan Bahu pada Pekerja Kantor dengan Komputer: Laporan Kasus Berbasis Bukti. J Indon Med Assoc. Vol. 67(10):592 - 598.

Soysal, A. N. O. dan Aslan, U. B. 2013. Treatment of chronic neck pain by two combined physiotherapy programs: comparison of phonophoresis and ultrasound. Asian Biomedicine, Vol. 7(6):821-827. 